OPEN ACCESS

Edited by:

Francesco Morini,

Bambino Gesù Children Hospital

(IRCCS), Italy

Reviewed by:

Luca Pio,

Hôpital Robert Debré, France

Ernesto Leva,

University of Milan, Italy

*Correspondence:

Chao Zheng

zhchallen@163.com

Chunbao Guo

guochunbao@cqmu.edu.cn

guochunbao@foxmail.com

Specialty section

This article was submitted to

Pediatric Surgery,

a section of the journa

Frontiers in Surgery

Received: 08 November 2020

Accepted: 30 December 2020

Published: 25 January 2021

Citation:

Liu Q, Gao K, Zheng C and Guo C

(2021) The Risk Factors for

Perioperative Serum Albumin Variation in Pediatric Patients Undergoing Major

Gastroenterology Surgery.

Front. Surg. 7:627174.

doi: $10.3389 /$ fsurg.2020.627174

\section{The Risk Factors for Perioperative Serum Albumin Variation in Pediatric Patients Undergoing Major Gastroenterology Surgery}

\author{
Qingshuang Liu ${ }^{1,2}, K^{2}$ Gao $^{1,2}$, Chao Zheng ${ }^{2,3 *}$ and Chunbao Guo ${ }^{1,2 *}$ \\ ${ }^{1}$ Department of Pediatric General and Neonatal Surgery, Children's Hospital, Chongqing Medical University, Chongqing, \\ China, ${ }^{2}$ Ministry of Education Key Laboratory of Child Development and Disorders, Chongqing Key Laboratory of Pediatrics, \\ National Clinical Research Center for Child Health and Disorders, China International Science and Technology Cooperation \\ Base of Child Development and Critical Disorders, Chongqing Engineering Research Center of Stem Cell Therapy, Children's \\ Hospital of Chongqing Medical University, Chongqing, China, ${ }^{3}$ Department of Orthopedics, Children's Hospital, Chongqing \\ Medical University, Chongqing, China
}

Background: The albumin, a negative acute-phase protein, is important for perioperative morbidity, even in patients with normal preoperative levels. This study intend to determine the perioperative factors related with the postoperative reduction in serum albumin $(\triangle \mathrm{ALB})$ and its influence on perioperative outcome in a pediatric general surgical cohort.

Methods: This single-center retrospective review included 939 pediatric patients who underwent major gastroenterology surgery from August 2010 to August 2019. The patients were dichotomized into a high $\triangle$ ALB group $(\geq 14.6 \%)$ and a low $\triangle$ ALB group $(<14.6 \%)$ based on the mean value of $\triangle A L B(14.6 \%)$. the independent risk factors for $\triangle \mathrm{ALB}$, were explored using the propensity score matching to minimize potential selection bias and subjected to method multivariable logistic regression model. Furthermore, in 366 matched patients, the influences of operating time on perioperative outcomes were analyzed.

Results: Among the 996 patients reviewed, 939 patient records were enrolled in the final analysis. Controlling for other factors, multivariable analysis showed that a high CRP on POD 3 or 4 [odds ratio $(\mathrm{OR})=2.36(95 \% \mathrm{Cl}, 1.51-3.86) ; p=0.007$ ], a longer operating time $[\mathrm{OR}=1.18(95 \% \mathrm{Cl}, 1.00-1.53) ; p=0.014)$, and the presence of Charcot's triad $[\mathrm{OR}=1.73(95 \% \mathrm{Cl}, 1.05-2.83) ; p=0.031]$ were factors that predicted a high $\triangle \mathrm{ALB}$ level. A high $\triangle$ ALB level was also related with gastrointestinal functional recovery delay, reflected by the postoperative defecation $(p=0.013)$ and bowel movement $(p=0.019)$ delay and the high occurrence of postoperative complications (16.1 vs. 10.9\%, OR, 1.57; 95\% Cl, 1.02-2.41, $P=0.0026)$.

Conclusions: The high $\triangle$ ALB level was correlated with postoperative outcome. To obtain a safe recovery and discharge after a major abdominal operation, the above risk factors for $\triangle \mathrm{ALB}$ could be addressed in the perioperative period.

Keywords: ALB, Roux-en-Y hepaticojejunostomy, postoperative recovery, perioperative complications, pediatric patients 


\section{BACKGROUND}

As an acute-phase protein, albumin (ALB) usually negatively responds to surgical stress, injury or sepsis $(1,2)$. A decrease in plasma albumin concentration is considered one of the features of systemic inflammation due to the loss of albumin to the tissue spaces $(3,4)$ and postoperative infectious complications $(4)$. The transcapillary leakage of albumin can be elevated by more than $300 \%$ in systemic inflammatory pathogenesis $(5,6)$. Preoperative hypoalbuminemia has also been confirmed as an indicator for poor nutritional status, and postoperative complication after spine surgery (7), GI surgery (8), and acute kidney injury (9). Because albumin has quick kinetics after surgery, which can even occur earlier than that of CRP, making it an intense focus of perioperative management $(10,11)$.

A sharp decrease of $33 \%$ in serum ALB within 2 days has been observed after major abdominal surgery $(2,12)$. There are many factors that may potentially impact the reduction in ALB level ( $\triangle \mathrm{ALB}$ ), including the pathology being treated and the actual procedure undertaken (13). Few studies have examined the factors that could be used to predict postoperative hypoalbuminemia in pediatric patients after major gastroenterology surgery. A clear evaluation of these factors could lead to the development of optimized perioperative care protocols.

We intended to explore the risk factors for the reduction in ALB by retrospectively reviewing data on pediatric patients that had undergone major gastroenterological surgery. We further sought to clarify the association between $\triangle \mathrm{ALB}$ and postoperative recovery and outcomes.

\section{METHODS}

\section{Population Selection}

This retrospective study included 996 consecutive patients managed with elective Roux-en-Y hepaticojejunostomy from August 12, 2010 to August 28, 2019 at our institute. Exclusion criteria included patients with preoperative or postoperative day (POD 1) ALB administration or subjects with incomplete laboratory data. The study protocol was approved by the Ethics Committee of Chongqing Medical University.

\section{Data Collection and Definitions}

Electronic medical records generated upon admission or referral were individually reviewed by 2 -well-trained clinical investigators who collected the relevant data. Data extraction included (1) preoperative data, including demographic data and clinical details, such as preoperative neutrophils, lymphocytes, hemoglobin, preoperative CRP and ALB, and pre-existing comorbidities; (2) intraoperative variables, including surgical

Abbreviations: ALB, albumin; ALP, alkaline phosphatase; ALT, alanine aminotransferase; $\triangle \mathrm{ALB}$, reduction in ALB level; ASA, American Society of Anesthesiology; AST, aspartate aminotransferase; BUN, blood urea nitrogen; CBD, Common bile duct; CI, confidence interval; CRP, C-reactive protein; $\gamma$-GTP, gamma-glutamyl transpeptidase; $\mathrm{Hb}$, hemoglobin; $\mathrm{LDH}$, lactate dehydrogenase; OR, odds ratio; POD, postoperative day; Scr, serum creatinine; SD, standard deviation; WBC, white blood cell. procedures (surgical approach, type of resection) and (3) postoperative outcomes, gastrointestinal function recovery features and postoperative complications. The involved laboratory data were usually collected preoperatively and on

TABLE 1 | Univariate analyses of perioperative factors associated with $\triangle$ ALB.

\begin{tabular}{|c|c|c|c|}
\hline & \multicolumn{3}{|c|}{ Total Population } \\
\hline & $\Delta A L B \geq 14.6 \%(471)$ & $\Delta$ ALB $<14.6 \%(468)$ & $p$-values \\
\hline Age (yrs), mean $\pm \mathrm{SD}$ & $2.13 \pm 1.02$ & $2.16 \pm 1.07$ & $0.21^{*}$ \\
\hline Female: Male & $183(37.5)$ & 191 (39.9) & $0.31 \$ \$$ \\
\hline $\begin{array}{l}\text { Weight }(\mathrm{kg}) \text {, mean } \pm \\
\text { SD }\end{array}$ & $11.38 \pm 2.96$ & $11.52 \pm 3.68$ & $0.22^{\star \star}$ \\
\hline BMI, median (range) & $24(20-30)$ & $25(21-31)$ & $0.13^{\star \star \star}$ \\
\hline \multicolumn{4}{|l|}{ Laboratory findings } \\
\hline $\begin{array}{l}\text { Hypertransaminasemia, } \\
n(\%)\end{array}$ & $325(69.0)$ & $334(71.4)$ & $0.47 \$ \$$ \\
\hline $\begin{array}{l}\text { Hyperbilirubinemia, } n \\
(\%)\end{array}$ & $186(39.5)$ & $173(37.0)$ & $0.39 \$ \$$ \\
\hline $\begin{array}{l}\text { Preoperative ALB } \\
(\mathrm{g} / \mathrm{L}), \text { mean } \pm \mathrm{SD}\end{array}$ & $39.28 \pm 4.72$ & $41.41 \pm 5.39$ & $0.016^{\star}$ \\
\hline $\begin{array}{l}\text { Preoperative CRP } \\
(\mathrm{g} / \mathrm{L}), \text { mean } \pm \mathrm{SD}\end{array}$ & $11.24 \pm 3.26$ & $12.56 \pm 4.17$ & $0.15^{\star}$ \\
\hline $\begin{array}{l}\text { Preoperative WBC } \\
(109 / L), \text { mean } \pm \text { SD }\end{array}$ & $7.9 \pm 2.8$ & $8.2 \pm 3.1$ & $0.52^{*}$ \\
\hline \multicolumn{4}{|c|}{ Ultrasound presentation } \\
\hline $\begin{array}{l}\text { Mean } \mathrm{CBD}(\mathrm{cm}), \text { mean } \\
\pm \mathrm{SD}\end{array}$ & $1.53 \pm 0.58$ & $2.34 \pm 0.97$ & $0.042^{\star \star}$ \\
\hline Charcot's triad, $n(\%)$ & $142(30.1)$ & 109 (23.3) & $0.011 \$ \$$ \\
\hline $\begin{array}{l}\text { Nadir ALB within POD } \\
2 \text { (g/L), mean } \pm S D\end{array}$ & $34.94 \pm 8.92$ & $30.22 \pm 7.83$ & $0.0012^{*}$ \\
\hline $\begin{array}{l}\text { CRP on POD } 3 \text { or } 4 \\
(\mathrm{mg} / \mathrm{L}), \text { mean } \pm \mathrm{SD}\end{array}$ & $41.45 \pm 13.65$ & $29.8 \pm 7.69$ & $<0.001^{*}$ \\
\hline $\begin{array}{l}\text { Postoperative WBC } \\
(109 / L), \text { mean } \pm \text { SD }\end{array}$ & $15.8 \pm 4.9$ & $14.9 \pm 4.8$ & $0.350^{\star}$ \\
\hline \multicolumn{4}{|c|}{ Mode of surgical approach, $n(\%)$} \\
\hline Laparoscopic & $168(35.7)$ & $139(29.7)$ & \\
\hline Open & $303(64.3)$ & $329(70.3)$ & $0.03 \$ \$$ \\
\hline $\begin{array}{l}\text { Operation time, } \\
\text { median (range), min }\end{array}$ & $175(132-418)$ & $143(115-367)$ & $0.0024^{\star \star \star}$ \\
\hline $\begin{array}{l}\text { Nadir of hemoglobin } \\
(\mathrm{g} / \mathrm{L})\end{array}$ & $9.18 \pm 1.32$ & $9.64 \pm 1.68$ & $0.28^{*}$ \\
\hline $\begin{array}{l}\text { Operative blood loss } \\
(\mathrm{mL}), \text { mean } \pm \mathrm{SD}\end{array}$ & $36.78 \pm 16.84$ & $33.86 \pm 15.88$ & $0.26^{*}$ \\
\hline $\begin{array}{l}\text { Intraoperative fluid } \\
\text { utilization (mL/kg*h), } \\
\text { mean } \pm \mathrm{SD}\end{array}$ & $16.74 \pm 6.88$ & $14.26 \pm 6.72$ & $0.017^{\star}$ \\
\hline $\begin{array}{l}\text { Intraoperative } \\
\text { transfusion, } n \text { (\%) }\end{array}$ & $131(27.8)$ & $115(24.6)$ & $0.15 \$ \$$ \\
\hline \multicolumn{4}{|l|}{ ASA classification } \\
\hline ASA1-2 & 338 (72.6) & $319(67.7)$ & $0.13 \$ \$$ \\
\hline ASA3-4 & $133(27.4)$ & $149(22.3)$ & \\
\hline
\end{tabular}

$A L B$, albumin; $\triangle A L B$, reduction of ALB level; $A S A$, American Society of Anesthesiology; $C B D$, Common bile duct; $C R P, C$-reactive protein; $P O D$, postoperative day; $S D$, standard deviation; WBC, white blood cell.

Statistical methods: " Student's t-test; " Mann-Whitney U test; ${ }^{* * *}$ Wilcoxon rank-sum test; $\$ \$$ Pearson's $\times 2$ test. 
PODs 3 and 7. Gastrointestinal function recovery were evaluated within the postoperative days 5 , including the postoperative flatus or defecation, time to normal diet, etc. The postoperative complications were ranked following the Clavien-Dindo classification system (14), such as intra-abdominal abscesses, postoperative hemorrhage, anastomotic fistula, anastomotic stenosis, etc.

The relative serum albumin change $(\triangle \mathrm{ALB})$ was calculated as (preoperative albumin-nadir albumin level within POD 2)/preoperative albumin $\times 100 \%(15)$. We evaluated $\triangle A L B$ as normally distributed data and decided to use the mean value of the $(14.6 \%)$ to dichotomize the groups. The patients were divided with a low $(<14.6 \%)$ and a high $(\geq 14.6 \%) \triangle \mathrm{ALB}$ group based on the cutoff value (14.6\%).

The primary outcome based on $\triangle \mathrm{ALB}$ was prompt postoperative gastrointestinal function recovery. The secondary outcomes were postoperative complications and immunologic and inflammatory variables. Gastrointestinal symptoms, like first bowel movement (gas and feces), vomiting, abdominal bloating, abdominal cramps, were assessed and recorded daily for within the postoperative days 5 .

\section{Propensity Scores and Matching and Statistical Analysis}

The propensity score matching was firstly performed to minimize selection biases using SPSS 20.0 (IBM, Armonk, NY) or R 3.1.2 (The R Foundation for Statistical Computing). The selected variables entered into the propensity model were demographic data, laboratory values, treatment protocols, surgical features, etc. The assumption of linearity of the PS model was checked using the generalized additive model, subsequently matching 366 patients with high $\triangle \mathrm{ALB} \geq 14.6 \%$ and 366 patients with $\triangle \mathrm{ALB}$ $<14.6 \%$. The perioperative outcomes between the two groups were compared after propensity score matching.

To verify independent predictors for postoperative complications, multivariate analysis was performed using multivariate logistic regression analysis after univariate analysis to identify predictors with a significance level of $P<0.30$ (Table 3). The results of the multivariate logistic regression

TABLE 2 | Multivariate analysis of perioperative factors associated with $\triangle A L B$.

\begin{tabular}{lccc}
\hline & OR & $\mathbf{9 5 \%} \mathbf{C l}$ & $\boldsymbol{P}$ \\
\hline $\mathrm{BMI}>26$ & 1.26 & $(0.97-1.89)$ & 0.16 \\
Preoperative ALB $<32 \mathrm{~g} / \mathrm{L}$ & 1.68 & $(0.91-2.35)$ & 0.27 \\
Preoperative CRP $>12 \mathrm{~g} / \mathrm{L}$ & 1.12 & $(0.94-1.73)$ & 0.18 \\
CRP on POD 3 or $4(>135 \mathrm{mg} / \mathrm{L})$ & 2.36 & $(1.51-3.86)$ & 0.007 \\
Charcot's triad & 1.73 & $(1.05-2.83)$ & 0.031 \\
Operation time(>165 m) & 1.18 & $(1.01-1.53)$ & 0.014 \\
Open surgical approach & 2.31 & $(0.89-4.76)$ & 0.31 \\
Intraoperative fluid utilization $>17 \mathrm{~mL} / \mathrm{kg}^{*} \mathrm{~h}$ & 1.07 & $(0.96-1.78)$ & 0.22 \\
Intraoperative transfusion & 1.38 & $(0.98-2.16)$ & 0.092 \\
ASA classification(ASA1-2) & 1.74 & $(0.96-3.24)$ & 0.39 \\
\hline
\end{tabular}

Statistical methods: multivariate logistic regression analysis. analysis were expressed using the $P$-value, odds ratio (OR), and $95 \%$ confidence interval (CI). To assess the postoperative outcomes, categorical and continuous variables were analyzed using Fisher's exact test or Pearson's $\chi 2$ test as well as Student's $t$-test or Mann-Whitney $U$ test and the Wilcoxon rank-sum test, as appropriate. In all cases, $P<0.05$ was considered significant.

\section{RESULTS}

\section{Patient Population}

For the whole 996 pediatric patients underwent hepaticojejunostomy resection in our department, $41 \mathrm{did}$

TABLE 3 | The inclusion variables in the PS-matching analysis.

\begin{tabular}{|c|c|c|c|}
\hline & \multicolumn{3}{|c|}{ Total Population } \\
\hline & $\Delta A L B \geq 14.6 \%(366)$ & $\Delta \mathrm{ALB}<14.6 \%(366)$ & $p$-values \\
\hline Age (yrs) & $2.14 \pm 1.01$ & $2.15 \pm 1.03$ & $0.45^{\star}$ \\
\hline Female: Male & $135(36.9)$ & $136(37.2)$ & $0.50 \$ \$$ \\
\hline Weight (kg) & $11.44 \pm 2.76$ & $11.46 \pm 3.11$ & $0.34^{\star}$ \\
\hline BMI, median (range) & $25(21-28)$ & $25(21-29)$ & $0.28^{\star \star \star}$ \\
\hline \multicolumn{4}{|l|}{ Laboratory findings } \\
\hline $\begin{array}{l}\text { hypertransaminasemia, } \\
n(\%)\end{array}$ & $252(68.9)$ & $251(68.6)$ & $0.50 \$ \$$ \\
\hline $\begin{array}{l}\text { hyperbilirubinemia, } n \\
\text { (\%) }\end{array}$ & $146(39.9)$ & $143(39.1)$ & $0.44 \$ \$$ \\
\hline $\begin{array}{l}\text { Preoperative ALB } \\
(\mathrm{g} / \mathrm{L}) \text {, mean } \pm \mathrm{SD}\end{array}$ & $39.83 \pm 4.26$ & $40.63 \pm 4.96$ & $0.18^{\star}$ \\
\hline $\begin{array}{l}\text { Preoperative CRP } \\
(\mathrm{g} / \mathrm{L}) \text {, mean } \pm \mathrm{SD}\end{array}$ & $11.87 \pm 3.16$ & $12.04 \pm 3.88$ & $0.35^{\star}$ \\
\hline $\begin{array}{l}\text { Preoperative WBC } \\
\text { (109/L), mean } \pm \text { SD }\end{array}$ & $8.01 \pm 2.62$ & $8.14 \pm 2.69$ & $0.39^{*}$ \\
\hline \multicolumn{4}{|c|}{ Ultrasound presentation } \\
\hline $\begin{array}{l}\text { Mean } \mathrm{CBD}(\mathrm{cm}) \\
\text { mean } \pm \mathrm{SD}\end{array}$ & $1.75 \pm 0.53$ & $2.07 \pm 0.86$ & $0.18^{\star \star}$ \\
\hline $\begin{array}{l}\text { Nadir ALB within POD } \\
2 \text { (g/L), mean } \pm \text { SD }\end{array}$ & $33.13 \pm 8.56$ & $32.34 \pm 7.69$ & $0.23^{\star}$ \\
\hline $\begin{array}{l}\text { Postoperative WBC } \\
\text { (109/L), mean } \pm \text { SD }\end{array}$ & $15.56 \pm 4.64$ & $15.12 \pm 4.63$ & $0.46^{*}$ \\
\hline \multicolumn{4}{|c|}{ Mode of surgical approach, $n(\%)$} \\
\hline Laparoscopic & $131(35.8)$ & $126(34.4)$ & \\
\hline Open & $235(64.2)$ & $240(65.6)$ & $0.38 \$ \$$ \\
\hline $\begin{array}{l}\text { Nadir of hemoglobin } \\
(\mathrm{g} / \mathrm{L})\end{array}$ & $9.35 \pm 1.25$ & $9.48 \pm 1.52$ & $0.33^{\star}$ \\
\hline $\begin{array}{l}\text { Operative blood loss } \\
(\mathrm{mL})\end{array}$ & $35.16 \pm 14.69$ & $34.47 \pm 13.53$ & $0.29^{\star}$ \\
\hline $\begin{array}{l}\text { Intraoperative fluid } \\
\text { utilization }\left(\mathrm{mL} / \mathrm{kg}^{*} \mathrm{~h}\right) \\
\text { mean } \pm \mathrm{SD}\end{array}$ & $15.59 \pm 6.54$ & $14.93 \pm 6.18$ & $0.27^{\star}$ \\
\hline $\begin{array}{l}\text { Intraoperative } \\
\text { transfusion, } n(\%)\end{array}$ & $102(27.9)$ & $98(26.8)$ & $0.40 \$ \$$ \\
\hline \multicolumn{4}{|l|}{ ASA classification } \\
\hline ASA1-2 & $262(71.6)$ & $257(70.2)$ & $0.37 \$ \$$ \\
\hline ASA3-4 & $104(28.4)$ & $109(29.8)$ & \\
\hline
\end{tabular}

Statistical methods: *Student's t-test; **Mann-Whitney U test; *** Wilcoxon rank-sum test; $\$ \$$ Pearson's $\times 2$ test. 
TABLE 4 | Outcome characteristics in the matched population depended on the mean value of $\triangle A L B$.

\begin{tabular}{|c|c|c|c|c|}
\hline & $\Delta A L B>14.6 \%(366)$ & $\Delta$ ALB $<14.6 \%(366)$ & $p$-values & Odds ratio $(95 \% \mathrm{Cl})$ \\
\hline Hypotensive events, n (\%) & $42(10.47)$ & $38(11.88)$ & $0.36^{\star}$ & \\
\hline Norepinephrine usage, $n$ (\%) & 45 (13.95) & $40(12.17)$ & $0.32 \$ \$$ & \\
\hline Furosemidum, $n(\%)$ & $36(9.88)$ & $34(11.30)$ & $0.50 \$ \$$ & \\
\hline Metabolic acidosis, $n$ (\%) & $18(3.20)$ & $13(4.93)$ & $0.23 \$ \$$ & \\
\hline Hypokalemic episodes, $n$ (\%) & 24 & 25 & $0.50 \$ \$$ & \\
\hline \multicolumn{5}{|l|}{ Serum albumin } \\
\hline First defecation (days) & $3.13 \pm 1.32$ & $2.88 \pm 1.27$ & $0.12^{\star}$ & \\
\hline First flatus & $3.56 \pm 0.88$ & $3.07 \pm 0.90$ & $0.013^{*}$ & \\
\hline First bowel movement (days), Mean \pm SD & $2.75 \pm 0.82$ & $2.14 \pm 0.78$ & $0.019^{\star \star}$ & \\
\hline Stool within $72 \mathrm{~h}, n(\%)$ & $123(32.75)$ & $147(40.12)$ & $0.039 \$ \$$ & $1.33(0.98-1.79)$ \\
\hline Abdominal distension, $n(\%)$ & $36(13.5)$ & $28(19.8)$ & $0.18 \$ \$$ & \\
\hline Diarrhea, $n(\%)$ & $23(6.8)$ & $21(10.9)$ & $0.50 \$ \$$ & \\
\hline Vomiting, $n$ (\%) & $35(13.0)$ & $31(16.1)$ & $0.38 \$ \$$ & \\
\hline No. of patients with mild complications, n(\%) & $45(11.7)$ & $29(9.0)$ & $0.033 \$ \$$ & $1.63(1.00-2.66)$ \\
\hline No. of patients with major complications, $n(\%)$ & $28(7.7)$ & 21 & 0.19 & \\
\hline Total number of complications, $n$ (\%) & $59(16.1)$ & 40 (10.9) & 0.026 & $1.57(1.02-2.41)$ \\
\hline Length of stay $(d)$, mean \pm SD & $8.19 \pm 3.16$ & $7.69 \pm 2.67$ & 0.057 & \\
\hline
\end{tabular}

Statistical methods: *Student's t-test; ** Mann-Whitney U test; \$\$ Pearson's $\chi 2$ test.

not fulfill the inclusion criteria and were initially excluded, and sixteen patients were excluded because their notes were unobtainable for data extraction. Finally, a total of 939 patient records were enrolled in the final analysis (Table 1).

\section{Factors Associated With $\triangle A L B$}

The baseline features of the $\triangle \mathrm{ALB} \geq 14.6 \%$ and $\triangle \mathrm{ALB}<14.6 \%$ groups are summarized in Table 1. A larger choledochal cyst size $(p=0.042)$, worse comorbidity (Charcot's triad) $(p=0.011)$, lower preoperative ALB $(p=0.016), \mathrm{CRP}$ on POD 3 or $4(p$ $<0.001)$, and a longer surgery duration $(p=0.0024)$ were associated with a greater $\triangle \mathrm{ALB}(P<0.05)$ in the univariable analysis. Multivariable analysis revealed three independent risk factors (Table 2) associated with $\triangle \mathrm{ALB}$, including, CRP on POD 3 or $4[\mathrm{OR}=2.36(95 \% \mathrm{CI}, 1.51-3.86) ; p=0.007]$, the presence of Charcot's triad [OR $=1.73$ (95\% CI, 1.05-2.83); $p=0.031$ ], and a longer operating time $[\mathrm{OR}=1.18$ (95\% CI, 1.00-1.53); $p$ $=0.014]$.

\section{Influences of $\triangle A L B$ on Postoperative Outcomes}

To explore the association between $\triangle \mathrm{ALB}$ and perioperative outcome, we performed PS matching between the $\triangle \mathrm{ALB} \geq 14.6 \%$ and $\triangle \mathrm{ALB}<14.6 \%$ groups. Under PS matching, 366 patients in the $\triangle \mathrm{ALB} \geq 14.6 \%$ group were matched to 366 patients in the $\triangle \mathrm{ALB}<14.6 \%$ group (Table 3 ).

In the propensity matched cohort, patients with $\triangle \mathrm{ALB}<$ $14.6 \%$ had reduced time for postoperative flatus $(p=0.013)$ and postoperative bowel movement $(p=0.019$ ) (Table 4). In the $\triangle \mathrm{ALB}<14.6 \%$ group, $40.2 \%(147 / 366)$ of patients passed stool within $72 \mathrm{~h}$, and $33.6 \%(123 / 366)$ of patients with high $\triangle \mathrm{ALB}$ passed stool (OR, 1.33; 95\% CI, 0.98-1.79, $p=0.039$ ). The incidences of diarrhea $(p=0.50)$, vomiting $(p=0.38)$ and abdominal distention $(p=0.18)$ within 5 PODs were similar between the two groups.

As shown in Table 4, more total complications, like anastomotic leakage, intraperitoneal abscess, surgical site infections, were found in patients with $\triangle \mathrm{ALB} \geq 14.6 \%$ than those with $\triangle \mathrm{ALB}<14.0 \%$ (16.1 vs. $10.9 \%$, OR, 1.57 ; $95 \% \mathrm{CI}$, $1.02-2.41, P=0.0026)$. In addition, the postoperative stay was $8.19 \pm 3.16$ days in the $\triangle \mathrm{ALB} \geq 14.0 \%$ group, which was longer than that of the $\triangle \mathrm{ALB}<14.0 \%$ group $(7.69 \pm 2.67$ days $)$, although no statistically significant difference was observed $(p$ $=0.057$ ).

\section{DISCUSSION}

We conducted the present analysis to focus on serum albumin as an acute phase protein for the pediatric patients managed with major gastroenterology surgery. This study revealed that several factors were associated with high $\triangle \mathrm{ALB}$, such as operative duration, disease comorbidities, and mean CBD. Furthermore, a greater decrease in serum albumin were associated with delay in gastrointestinal function recovery, more complications, and prolonged postoperative hospital stay.

The factors leading to hypoalbuminemia are often complicated and associated with operative case type, ALB loss, redistribution, catabolism, or theirs combination $(2,15-17)$. Numerous researches have focused on hypoalbuminemia as risk factors for postoperative complications $(7,18)$, while few have specifically stressed the perioperative factors related to $\triangle \mathrm{ALB}$, which may be clinically significant for postoperative care. In the present study, several clinical factors related to the decrease in postoperative albumin were presented, including longer operating time, severe comorbidities, such as Charcot's triad, and high CRP. During surgery, manipulation of the intestine 
has been proven to initiate gastrointestinal edema $(19,20)$. The surgical stress response and postoperative edema might be attributed to the low colloid osmotic pressure and fluid accumulation, themselves resulting from a low postoperative $\triangle \operatorname{ALB}(2,5)$, which was consistent with the current findings.

The plasma albumin concentration was associated with altered distributions between the intravascular and extravascular space and plasma volume changes. The reasons for this association may pertain to hemodilution, which might contribute to the decreased albumin level after surgery. In our previous study (21), postoperative complications were shown to be related to conventional intraoperative and postoperative fluid usage, which might also affect the albumin level after surgery. Excessive fluid could also promote capillary leakage of serum albumin, which is common in some surgical trauma comdition $(6,22)$. Serum albumin on POD 3 has been observed to be correlated with preoperative CRP level $(13,23,24)$. In the current study, we indeed found that a high $\triangle \mathrm{ALB}$ was associated with CRP on POD 3 or 4 .

As indicated in the current study, although uneventful recovery was present for most patients following choledochal cyst resection, unfavorable postoperative gastroenterological recovery was associated with a high $\triangle \mathrm{ALB}$. Previous biological investigations have suggested that edema should delay the intestinal function recovery through directly affecting muscle function $(25,26)$. Serum ALB should account for postoperative intestinal edema after a major operation or severe trauma. Furthermore, fluid accumulation could decrease tissue oxygenation, which is also unfavorable for postoperative recovery and complications.

In the current research, we found the trend for complications increase in patients with high $\triangle \mathrm{ALB}$, including anastomotic leakage. A possible explanation at the tissue level may be that the low ALB level reduced the tissue connections with collagen deposition. The effect of $\triangle \mathrm{ALB}$ on the local inflammatory response and edema recovery is also important and might also explain postoperative recovery and complications $(27,28)$. It remains to be determined whether ALB supplementation reduces postoperative intestinal edema and cellular swelling in the pediatric population managed with major gastrointestinal surgery $(29,30)$.

In this research, several weakness should be considered during interpretation the main finding. First, the retrospective design may contribute to selection and treatment biases. Second, there might have been many practice changes over a long period of time in the single center study, which may be different from the current treatment algorithms. Another point of emphasis was that although baseline characteristics were similar after PS

\section{REFERENCES}

1. Wierdak M, Pisarska M, Kuśnierz-Cabala B, Witowski J, Dworak J, Major $\mathrm{P}$, et al. Changes in plasma albumin levels in early detection of infectious complications after laparoscopic colorectal cancer surgery with ERAS protocol. Surg Endosc. (2018) 32:3225-33. doi: 10.1007/s00464-018-6040-4 matching, the patients with high $\triangle \mathrm{ALB}$ might be surgically more difficult than those with low $\triangle$ ALB. More solid, multicenter prospective studies should be conducted with less confounding variables to determine the current conclusions.

\section{CONCLUSION}

In this research, we characterized some risk factors that may predispose patients to high $\triangle \mathrm{ALB}$, which could negatively impact postoperative recovery after a major abdominal operation in a pediatric population. The surgeons should be aware of $\triangle A L B$ in the early postoperative period to optimize the surgical care.

\section{DATA AVAILABILITY STATEMENT}

The original contributions generated for the study are included in the article/supplementary material, further inquiries can be directed to the corresponding author/s.

\section{ETHICS STATEMENT}

The studies involving human participants were reviewed and approved by the Ethics Committee of Chongqing Medical University. Written informed consent to participate in this study was provided by the participants' legal guardian/next of kin. Written informed consent was obtained from the individual(s), and minor(s)' legal guardian/next of kin, for the publication of any potentially identifiable images or data included in this article.

\section{AUTHOR CONTRIBUTIONS}

QL and KG designed and analyzed the data. CZ evaluated the manuscript and performed the statistical measurements. CG analyzed the data and wrote the paper. All authors contributed to the article and approved the submitted version.

\section{FUNDING}

This study was supported by grants from the Key Project of the Chongqing Natural Science Foundation (cstc2012jjA0155) for collection, analysis, and interpretation of data and the Chongqing Health Planning Commission of Research Fund (No: 2016MSXM044) for writing the manuscript.

\section{ACKNOWLEDGMENTS}

We thank Prof. Siqi Yang for providing insightful discussions during the preparation of the manuscript.

2. Norberg Å, Rooyackers O, Segersvärd R, Wernerman J. Albumin kinetics in patients undergoing major abdominal surgery. PLoS ONE. (2015) 10:e0136371. doi: 10.1371/journal.pone.0136371

3. Norberg Å, Rooyackers O, Segersvärd R, Wernerman J. Leakage of albumin in major abdominal surgery. Crit Care. (2016) 20:113. doi: 10.1186/s13054-016-1283-8 
4. Migita K, Matsumoto S, Wakatsuki K, Kunishige T, Nakade H, Miyao $\mathrm{S}$, et al. Postoperative serum C-reactive protein level predicts longterm outcomes in stage I gastric cancer. J Surg Res. (2019) 242:32331. doi: 10.1016/j.jss.2019.04.075

5. Fleck A, Raines G, Hawker F, Trotter J, Wallace PI, Ledingham IM, et al. Increased vascular permeability: a major cause of hypoalbuminaemia in disease and injury. Lancet. (1985) 1:781-4. doi: 10.1016/S0140-6736(85)91447-3

6. Nicholson JP, Wolmarans MR, Park GR. The role of albumin in critical illness. Br J Anaesth. (2000) 85:599-610. doi: 10.1093/bja/85.4.599

7. Adogwa O, Martin JR, Huang K, Verla T, Fatemi P, Thompson $\mathrm{P}$, et al. Preoperative serum albumin level as a predictor of postoperative complication after spine fusion. Spine. (2014) 39:1513-9. doi: 10.1097/BRS.0000000000000450

8. Rudasill SE, Morales RR, Sanaiha Y, Sareh S, Antonios JW, Khoury H, et al. Predicting morbidity and mortality in laparoscopic cholecystectomy: preoperative serum albumin still matters. Am J Surg. (2019) 220:4327. doi: 10.1016/j.amjsurg.2019.12.005

9. Cabezuelo JB, Ramírez P, Ríos A, Acosta F, Torres D, Sansano T, et al. Risk factors of acute renal failure after liver transplantation. Kidney Int. (2006) 69:1073-80. doi: 10.1038/sj.ki.5000216

10. Amouzandeh M, Nowak G, Januszkiewicz A, Wernerman J, Rooyackers O, Norberg A. Albumin mass balance and kinetics in liver transplantation. Crit Care. (2018) 22:152. doi: 10.1186/s13054-018-2053-6

11. Komáromi A, Estenberg U, Hammarqvist F, Rooyackers O, Wernerman J, Norberg Å. Simultaneous assessment of the synthesis rate and transcapillary escape rate of albumin in inflammation and surgery. Crit Care. (2016) 20:370. doi: 10.1186/s13054-016-1536-6

12. Dumitrescu G, Komaromi A, Rooyackers O, Klaude M, Hebert C, Wernerman J, et al. Repeated quantitative measurements of de novo synthesis of albumin and fibrinogen. PLoS ONE. (2017) 12:e0174611. doi: 10.1371/journal.pone.0174611

13. Sonoda A, Ohnishi S, Nakao S, Iwashita $\mathrm{Y}$, Hashimoto $\mathrm{N}$, Ishida $\mathrm{K}$, et al. Factors affecting serum albumin in the perioperative period of colorectal surgery: a retrospective study. BMC Res Notes. (2015) 8:638. doi: 10.1186/s13104-015-1632-8

14. Dindo D, Demartines N, Clavien PA. Classification of surgical complications: a new proposal with evaluation in a cohort of 6336 patients and results of a survey. Ann Surg. (2004) 240:205-13 doi: 10.1097/01.sla.0000133083.54934.ae

15. Giovannini I, Chiarla C, Giuliante F, Vellone M, Ardito F, Nuzzo G. The relationship between albumin, other plasma proteins and variables, and age in the acute phase response after liver resection in man. Amino Acids. (2006) 31:463-9. doi: 10.1007/s00726-005-0287-5

16. Ruot B, Papet I, Bechereau F, Denis P, Buffiere C, Gimonet J, et al. Increased albumin plasma efflux contributes to hypoalbuminemia only during early phase of sepsis in rats. Am J Physiol Regul Integr Comp Physiol. (2003) 284:R707-13. doi: 10.1152/ajpregu.00483.2002

17. Labgaa I, Joliat GR, Kefleyesus A, Mantziari S, Schäfer M, Demartines $\mathrm{N}$, et al. Is postoperative decrease of serum albumin an early predictor of complications after major abdominal surgery? A prospective cohort study in a European centre. BMJ Open. (2017) 7:e013966. doi: 10.1136/bmjopen-2016-013966

18. Labgaa I, Joliat GR, Demartines N, Hübner M. Serum albumin is an early predictor of complications after liver surgery. Dig Liver Dis. (2016) 48:55961. doi: 10.1016/j.dld.2016.01.004
19. Boelens PG, Heesakkers FF, Luyer MD, van Barneveld KW, de Hingh IH, Nieuwenhuijzen GA, et al. Reduction of postoperative ileus by early enteral nutrition in patients undergoing major rectal surgery: prospective, randomized, controlled trial. Ann Surg. (2014) 259:64955. doi: 10.1097/SLA.0000000000000288

20. Ozacmak HS, Ozacmak VH, Barut F, Arasli M, Ucan BH. Pretreatment with mineralocorticoid receptor blocker reduces intestinal injury induced by ischemia and reperfusion: involvement of inhibition of inflammatory response, oxidative stress, nuclear factor $\kappa \mathrm{B}$, and inducible nitric oxide synthase. J Surg Res. (2014) 191:350-61. doi: 10.1016/j.jss.2014.04.040

21. Tan X, Liu J, Guo C. Crystalloid administration is associated with the recovery of pediatric elective Roux-en-Y hepaticojejunostomy. Eur J Pediatr Surg. (2019) 30:187-92. doi: 10.1055/s-0038-1677544

22. Lee WL, Slutsky AS. Sepsis and endothelial permeability. N Engl J Med. (2010) 363:689-91 doi: 10.1056/NEJMcibr1007320

23. Bona D, Micheletto G, Bonitta G, Panizzo V, Cavalli M, Rausa E, et al. Does Creactive protein have a predictive role in the early diagnosis of postoperative complications after bariatric surgery? Systematic review and Bayesian metaanalysis. Obes Surg. (2019) 29:3448-56. doi: 10.1007/s11695-019-04013-0

24. Hao F, Guo H, Zhong J, Geng Q, Yang Y, Chen B, et al. Effects of prostaglandin e1 on patients undergoing major gastrointestinal surgery. Ann Surg. (2018) 267:759-65. doi: 10.1097/SLA.0000000000002152

25. Kinsky MP, Milner SM, Button B, Dubick MA, Kramer GC. Resuscitation of severe thermal injury with hypertonic saline dextran: effects on peripheral and visceral edema in sheep. J Trauma. (2000) 49:84453. doi: 10.1097/00005373-200011000-00009

26. Zanoni FL, Cruz JW, Martins JO, Benabou S, Greco KV, Moreno AC, et al. Hypertonic saline solution reduces mesenteric microcirculatory dysfunctions and bacterial translocation in a rat model of strangulated small bowel obstruction. Shock. (2013) 40:35-44. doi: 10.1097/SHK.0b013e318299d3fa

27. Rasslan R, Utiyama EM, Marques GM, Ferreira TC, da Costa VA, de Victo NC, et al. Inflammatory activity modulation by hypertonic saline and pentoxifylline in a rat model of strangulated closed loop small bowel obstruction. Int J Surg. (2014) 12:594-600. doi: 10.1016/j.ijsu.2014. 04.007

28. Vincent JL, De Backer D, Wiedermann CJ. Fluid management in sepsis: the potential beneficial effects of albumin. J Crit Care. (2016) 35:1617 doi: 10.1016/j.jcrc.2016.04.019

29. Vincent JL, Sakr Y, Reinhart K, Sprung CL, Gerlach H, Ranieri VM. 'Sepsis occurrence in acutely ill patients' Investigators. Is albumin administration in the acutely ill associated with increased mortality? Results of the SOAP study. Crit Care. (2005) 9:R745-54. doi: 10.1186/cc3895

30. Margarson MP, Soni N. Serum albumin: touchstone or totem? Anaesthesia. (1998) 53:789-803. doi: 10.1046/j.1365-2044.1998.00438.x

Conflict of Interest: The authors declare that the research was conducted in the absence of any commercial or financial relationships that could be construed as a potential conflict of interest.

Copyright (c) $2021 \mathrm{Liu}, \mathrm{Gao}$, Zheng and Guo. This is an open-access article distributed under the terms of the Creative Commons Attribution License (CC BY). The use, distribution or reproduction in other forums is permitted, provided the original author(s) and the copyright owner(s) are credited and that the original publication in this journal is cited, in accordance with accepted academic practice. No use, distribution or reproduction is permitted which does not comply with these terms. 